\title{
«TESTAMENT» DE MAHOMA DE ANZEYT, ALIAS «EL MARRANCHANO», PRESO EN 1466
}

\author{
Encarnación MARÍN PADILLA \\ CSIC - Madrid
}

Hace unos años publiqué en esta revista un artículo sobre la sospechosa conducta del alamín del lugar de Aranda, Mahoma de Ovecar ${ }^{1}$, vasallo de la noble familia aragonesa de los Ximénez de Urrea, señores de la villa de Épila y del vizcondado de Rueda. En esta ocasión vuelvo a referirme a otro vasallo de la misma familia, Mahoma de Anzeyt ${ }^{2}$, alias «el Marranchano» o «Marrachano», que vivió en lugares de la Ribera del río Xalon o Exalon, del citado señorío.

El presente trabajo, cuya base documental procede de los protocolos de Martín de Marín ${ }^{3}$, surgió tras el hallazgo del «testament», según el notario escribió al margen, de Mahoma de Anzeyt. Como tal instrumento público notarial no es sobresaliente ni usual. No reúne los requisitos propios de un testamento; no se especificaron lugar de sepultura, «legitima herencia», obras pías, limosnas, institución de herederos, etc. El interés de este instrumento público, que el propio Mahoma de Anzeyt consideró memorial, radica en que él estaba preso cuando hizo sus manifestaciones y en que era componente de una comunidad cuyos miembros, en contadas ocasiones, comparecieron para otorgar testamento público ante un notario cristiano ${ }^{4}$, si las comparamos con las veces que lo hicieron los componentes de las comunidades de judíos. En realidad, lo único que hizo Mahoma fue enumerar a todas las personas de las que era deudor, a todos sus acreedores, y el ganado que tenía; sólo recuerda a un testamento la petición a sus hijos de hacer determinada entrega a dos familiares.

Nuestro personaje, Mahoma de Anzeyt, alias «el Marranchano», era vecino de Lucena de la Ribera del río Xalon —hoy Lucena de Jalón-, lugar aragonés del señorío de los Ximénez de Urrea, cuando manifestó lo que él califica como

\footnotetext{
1 «Investigación sobre la conducta del alamín de Aranda, Mahoma de Ovecar, en 1489», AlQantara XIV (1993), 275-292.

${ }^{2}$ Escrito también Danzeyt, Danzeit y Danzait.

${ }^{3}$ Se conservan en el Archivo de Protocolos Notariales de La Almunia de Doña Godina. A sus siglas LA.APN. seguirá el nombre del notario, año, folios y, si se considera de interés, los testigos instrumentales.

${ }^{4}$ Los hacían ante el alfaquí de su comunidad. Entre otros y en los años 1461-1466: Mahoma de Artayut y Mahoma de Alcayne lo fueron de la de Calatorao; Mahoma Zanbriel lo fue de la de Lumpiaque; Ali Montero lo fue de la de Lucena; Mahoma Zanbriel, menor de días, y Juce Zanbriel lo fueron de la de Rueda; y Mahoma de Cepta y Mahoma la Bazia lo fueron de la de Urrea. En el
}

Al-Qanțara XXII, 2 (2001) 349-356 
memorial; y hacía siete años que había residido, temporalmente, en la villa de Épila.

El 2 de octubre de 1459, en la villa, Mahoma de Anzeyt prometió y se obligó «a seyer vasallo ultra que yo lo so del senyor don Lop Ximenez d'Urrea», por estar en el lugar de Lucena, «agora me fago vasallo» de dicho señor, «asi como vezino o casa stant» en Épila, «tanto quanto yo habitare e sere casa stant en la Ribera del rio Exalon». Luego se obligó «en poder del» justicia de la villa Juan de Tuo, «en nombre e voz de partida de hombres buenos ..., de dar e pagar de vezindat» al concejo «de signo servicio» diez sueldos anuales en el mes de abril, a partir del siguiente año ${ }^{5}$.

El cambio de vasallaje de Lucena a Épila con las franquezas, privilegios y libertades que, como tal, le correspondían, pudo ser personal. Mahoma se refirió a su casa, como era costumbre que hicieran los vasallos que tenían familia cuando trasladaban su residencia, pero no aludió a su mujer ni a sus hijos.

Quizá su estancia en Épila no mejoró su situación familiar ni económica, porque Mahoma de Anzeyt volvió a Lucena acompañado, si se fueron con él, de su mujer y sus hijos Mahoma, Avdalla y Ali de Anzeyt, menor de días ${ }^{6}$. En Lucena también vivían su hermano Ali, mayor de días ${ }^{7}$, otro hermano con su mismo nombre y apellido, Mahoma de Anzeyt, y una hermana, Fátima, madre de la sobrina de Mahoma que vivía en Alagón. Nuestro protagonista tenía, además, un «entenado» - hijastro-, Mahoma Cabanyas, y una «entenada» que vivía en Pinseque.

Como refleja el «testament» (según el notario, según él memorial), Mahoma de Anzeyt mantuvo una intensa actividad económica. Entregó préstamos y comandas y las recibió del rico judío de Zaragoza Juce Eli ${ }^{8}$ y de judíos de la villa de Épila, de los que fue deudor como otros muchos vasallos del señorío de los Ximénez de Urrea. Comandas entregadas en moneda, sobre todo aragonesa, sueldos y florines de oro, y en «panes», los cereales trigo, ordio, centeno y avena; de ellas solía responder Mahoma de Anzeyt con ganado de su propiedad.

caso de la viuda Amiri, por ejemplo, hizo su último testamento «viniendo a la muert», el sábado 5 de febrero del año 827 «al conto de los moros», y fue «recebido e testifficado por Calema Alamaqui, alfaqui de la aljama de los moros» de Zaragoza.

${ }^{5}$ Obligó su persona y bienes a hacerlo así (LA.APN., Martín de Marín, 1459, fol. 139v: testigo el escudero Ochona de Ortubia, procurador de don Lope Ximénez de Urrea).

${ }^{6}$ Mayor o menor de días, designación que acompañó a la persona cuando convivió con otra de su mismo nombre y apellido.

${ }^{7}$ En 1462 Ali de Anzeyt, alias «Marranchano», recibió dos comandas de judíos epilenses: el 31 de agosto de Salamon Levi y el 10 de diciembre de Abraham Alfrangil.

${ }^{8}$ Los judíos zaragozanos de la familia Eli llegaron a tener, a través de préstamos y comandas, buena parte del señorío de los Ximénez de Urrea en sus manos, tanto Juce como Abraham Eli. 
Parece que la fortuna de Mahoma de Anzeyt fue saneada, porque pudo tener un zapatero y un sastre «de su casa», que no fueron otros que los judíos epilenses Abraham Alfrangil y Mosse Sumiel. Parte de sus bienes la empleó en comprar ganado, lo que explicaría su alias, llegando a poseer en enero de 1466 dos yeguas, dos rocines, un asno, tres bueyes domados, dos novillos, doce cabezas de vacas entre chicas y grandes, cuarenta ovejas parideras, un cabrón y un carnero «para aldahea», y una cabra con tres «crianças», además de aves de corral.

Mahoma de Anzeyt mantuvo relaciones, entre otros, con componentes de su comunidad de Lucena, el alamín Mahoma el Carnicero, Mahoma Cihuena, Ybrahem de Codo, Juce de Codo, Mahoma Cabanyas, Mahoma Adolaziz y Mahoma el de Pina. Y con residentes en comunidades de moros de otros lugares: de Alfamén, Mahoma Alchinez; de Aranda, la mujer del alamín; de Cabañas, Mahoma el Guaxqui; de Calatorao, Muça Nabal; de Épila, el herrero Farax de Cepta, Mahoma el Castellano, Mahoma Navarro, Mahoma Adolaziz y Ali Adolaziz; de Lumpiaque, Ybrahem Gualit; de Morata, el alamín y su hijo; de Oblitas, Hamet el Tanbudo y su mujer; de Pinseque, Mahoma Talbot y su mujer, Fátima de Xariel; y de Rueda, Ali Feracayt, alias «Palomino».

Entre sus conocidos cristianos se encontraban: Juan Sánchez de Sarriá, merino de los judíos y moros de la señoría del virrey de Sicilia don Lope Ximénez de Urrea ${ }^{9}$, los escuderos epilenses Domingo de Arbúes, Pascual de Sarasa y Ochona de Ortubia, procurador del señor don Lope, los epilenses Antón Dolz, Pedro de Monrreal y Diego de Ortiga, y el clérigo Miguel de Lalanza, Miguel Serrano, Miguel Gil y Rodrigo de Borja; y de Salillas, lugar también de los Ximénez de Urrea, Juan Tirado, Juan de Bices, Pedro de Ortal, Antón Remón y su hijo Pedro.

Entre sus conocidos judíos con residencia en la villa de Épila se encontraban: de la familia de los Sumiel, el zapatero Abraham, Hahim ${ }^{10}$, Mosse, Salamon y Salamon Sumiel, menor y mayor de días, y Saya y Saya Sumiel, menor y mayor de días; de la familia de los Gallur, el zapatero Sento, el tejedor Acach y Acli; de la familia de los Bencida, Juce; de la familia Leredi, Juce; de la familia de los Abenforma, Acach; de la familia de los Abenpesat, Jehuda; y de la familia de los Alfrangil, Abraham y Sento. Además del ya citado judío de Zaragoza Juce Eli y del judío de Oblitas Mayr.

${ }^{9}$ En 1465 fue justicia de Épila, cargo que ocupó en 1466 Juan de San Juan.

${ }^{10} \mathrm{El} 17$ de octubre de 1464, Mahoma de Anzeyt, junto con Mahoma Talbot y su mujer, Fátima de Xariel, del lugar de Pinseque, recibieron en comanda de Hahim Sumiel doscientos sueldos y cuatro arrobas de trigo. De ellos sólo respondió el matrimonio con ochenta «cabrios de ovejas merinas», blancas y negras (LA.APN., Martín de Marín, 1464, fol. 86v: testigos, Diego de Ortiga, el judío Jehuda Abenpesat y el moro Mahoma Navarro, que residían en Épila). 
Un año largo antes de su encarcelamiento, concretamente el 5 de noviembre de 1464, en Épila, Mahoma, junto con su hermano Ali de Anzeyt y el también lucenero Ybrahem de Codo, recibieron a treudo del escudero Domingo de Arbués ${ }^{11}$ todos los campos que tenía en «la Guerta, si quiere termino de Agelio», tierra de campos propiedad de la orden de San Juan de Jerusalem, durante siete años, «seys collidas levantadas», y bajo las condiciones siguientes: en 1465 no recogerían cosecha porque dejarían los campos «a barbeytar»; sería la primera «collida» en 1466 y, a partir de entonces, pagarían anualmente de treudo dieciocho cahíces de trigo, «bello, linpio e mercadero, mesura de la villa, posados alli en la casa de Agelio»; la última cosecha recogida sería la de 1471, año en que tendrían que «relexar la mitat de los ditos campos, asi de los buenos como de los malos», para que el escudero pudiera arrendarlos a quien le pareciera; estaban obligados a «fazer todas e qualesquiere fazedurias» que el arrendador hubiera hecho durante los siete años, «excepto ad azut levado e acequia nueva». Cumpliendo todas las condiciones, el escudero los mantendría «en pascifica posesion» de los campos, se comprometía a no «tirarvos aquella por dar ad otri ninguno por mayor trehudo ni menor», y obligó sus bienes a cumplirlo. Mahoma, Ali e Ybrahem, «todos tres ensemble e cada uno de nos por si e por el todo», tomaron los citados campos del escudero durante los siguientes siete años y por dieciocho cahíces de trigo anuales, entregados en la casa de Agelio «a mision nuestra», a partir de 1466; y a cumplir las condiciones obligaron todos sus bienes, renunciaron a su «judge hordinario e local» y se sometieron a «complimiento de justicia por aquesta razon devant de qualquiere judge que ... nos querrades convertir, devant del qual o de los quales» prometieron llevar el juicio ${ }^{12}$. Qué lejos estaba de imaginar Mahoma de Anzeyt que no se ocuparía de esos campos ni recogería ninguna cosecha; pero no adelantemos acontecimientos.

El 24 de diciembre de 1464, en Épila, Mahoma de Anzeyt reconoció que había recibido en comanda del judío Juce Bencida ciento diez sueldos; cantidad de la que respondió con dos vacas y un «noviello anyal de pelo vermello» ${ }^{13}$.

Meses después, concretamente el 17 de abril de 1465, era a Mahoma de Anzeyt a quien le pagaba Pedro Remón cien sueldos, «devallan» de aquellos ciento noventa y cinco que él y su padre Antón Remón le debían en comanda ${ }^{14}$.

${ }^{11}$ A partir de aquí no especificaré la residencia de las personas citadas porque ya me he referido a ellas al hablar de las relaciones de Mahoma. Gualit.

${ }^{12}$ LA.APN., Martín de Marín, 1464, fols. 89-89v: testigos, Pedro de Ortal y el moro Ybrahem

${ }^{13}$ Dicho notario y año, fol. 101v: testigos, Miguel Gil, el judío Abraham Alfrangil y el moro Mahoma Adolaziz.

${ }^{14}$ Fechada el anterior 17 de enero en Épila; otorgó albarán (dicho notario, 1465, fol. 32: testigos, Antón Dolz y el herrero moro Farax de Cepta). 
Pasados unos días, el 6 de mayo de 1465, en Épila y sin revocar procuradores, Mahoma de Anzeyt daba poder a sus hijos Mahoma y Avdalla de Anzeyt, «absentes bien asi como si fuesen presentes, entramos a dos ensemble e a cada uno dellos por si etc. specialment e expresa a levar, traginar, vender, empenyar, canviar, feriar, permutar qualesquiere aberias, bienes e haveres mios mobles a qualesquiere personas etc. a recebir et fazer albaranes de recepta e a mostrar, si quiere presentar qualesquiere franquezas, privilegios e libertades mios e a jurar en anima mia que las sobreditas mercaderias son mias propias etc.» ${ }^{15}$.

Cuatro meses después, el 15 de septiembre en Epila, el judío Juce Leredi otorgaba a Mahoma de Anzeyt «difinimiento general ... de todos los deudos devidos por el ..., asi de dineros como de qualquiere natura de panes asi devidos, por virtut de contratos publicos como privados o en qualquiere otra manera, de todos los tiempos pasados entro al present e infrascripto dia e dio poder a mi notario los pudies hordinar tan largament quanto hordinar lo pudies al provecho del dito Mahoma etc.» ${ }^{16}$.

Había transcurrido justo un mes de ese definimiento general a Mahoma, cuando él y su hijo Ali recibieron en comanda del tejedor judío Acach Gallur el 15 de octubre de 1465, en Épila, veinte cahíces de trigo, «bello e mercadero, mesura de la villa de Epila» ${ }^{17}$.

Un mes y unos días antes de manifestar Mahoma su memorial en la cárcel, concretamente el 3 de diciembre de 1465, su hijo Ali de Anzeyt pagaba al judío Saya Sumiel, mayor de días, los quince cahíces de trigo que le debía ${ }^{18}$.

No constan los cargos ni las acusaciones presentadas contra Mahoma de Anzeyt, que terminaron con sus huesos en la cárcel y su procesamiento, ni se conocen los nombres de los testigos que comparecieron ni si se dio a Mahoma la posibilidad de defenderse de las faltas que se le imputaban o de justificar o explicar su conducta.

Las testificaciones acusatorias y de los testigos de defensa, si los hubo, las examinarían Ochona de Ortubia, procurador del señor don Lope Ximénez de Urrea, virrey de Sicilia y ausente de su villa de Épila en 1466, y Juan Sánchez de Sarriá, merino de los judíos y moros de la señoría del virrey. Ambos inter-

\footnotetext{
${ }^{15}$ Dicho notario y año, fol. 37: testigos, el escudero Pascual de Sarasa y el moro Juce de Codo.

${ }^{16}$ Dicho notario y año, fol. 78v: testigos, Juan Sánchez de Sarriá, el judío Mosse Sumiel y el moro Mahoma Adolaziz.

${ }^{17}$ Dicho notario y año, fol. 93v: testigos, Pedro de Monrreal, el judío Acach Abenforna y el moro Mahoma el Castellano.

${ }^{18}$ Según carta de comanda fechada el 9 de diciembre de 1459; otorgó albarán (dicho notario y año, fol. 113v: testigos, el clérigo Miguel de Lalanza, el judío Sento Alfrangil y el moro Ali Feracayt, alias «Palomino»).
} 
vendrían en un proceso de graves cargos, cuyo veredicto final, según el mismo preso temía, podía ser su condena a la pena capital.

El 24 de enero de 1466 se encontraba Mahoma de Anzeyt arrestado en la prisión del señor don Lope, que no era otra que la casa que tenía en Épila el citado merino Juan Sánchez de Sarriá. Allí manifestó ante el notario Martín de Marín: «quiero meter por memorial todos aquellos deudos que a mi de present me son devidos e aquellos qui por semblant yo devo a otri por tal, que si por ventura mis meritos bastaran a yo padecer pena de muert de mi persona, que entre todos los deudores e mis fillos non ayan debat ni discordia ninguna; por tanto quiero qui por el notario infracripto sian puestos por menudo».

Con expreso consentimiento del procurador del señor don Lope, el escudero Ochona de Ortubia, «a cuya merce yo de present so», Mahoma fue enumerando a sus acreedores «segunt la manera e forma que se sigue»:

Sus hijos tenían que pagar al zapatero judío Abraham Sumiel los seis cahíces de trigo que le prestó «graciosament, sinse carta ni obligacion ninguna»; tres cahíces el siguiente mes de agosto y el resto en dicho mes de 1467.

Se tenían que pagar al zapatero judío Sento Gallur los dos cahíces que le prestó «sinse carta».

Se tenían que pagar al judío Abraham Alfrangil los ocho cahíces de trigo que le prestó en comanda y que tenía que devolver en dos años, la mitad el siguiente mes de agosto y el resto en dicho mes de 1467; además de los cinco de avena que también tenía que devolver el siguiente mes de agosto, los cinco y tres arrobas de ordio, los diez sueldos, los dos pares de zapatos «sobresolados e engarlandados», y otro par de zapatos «de honbre nuevos». También le debía un cahíz y seis fanegas de trigo, por su hermana Fátima.

Debía en comanda al judío Juce Eli diez cahíces de trigo, que tenía que devolver durante los siguientes tres años; además de otros dos cahíces de trigo, por su hermana Fátima.

Debía y tenía que devolver en dos años al judío Saya Sumiel cinco cahíces de trigo, resto de los doce que le entregó en comanda.

Debía al judío Salamon Sumiel, mayor de días, un cahíz de trigo, resto de los cinco que le prestó en comanda.

Debía al judío Acach Gallur veinte cahíces de trigo que le prestó en comanda y que tenía que devolver en cuatro años, cinco arrobas de ordio y cuarenta y tres sueldos; además de cinco arrobas de trigo, por su hermana Fátima.

Debía a Hahim Sumiel: seis sueldos, unas «sobresuelas e engarlandados e unos çapatos», pero éste tenía suyos dos corderos en doce sueldos ocho dineros y siete pares de gallinas que dejó en su casa; quince cahíces de trigo «sinse carta», que devolvería en tres años, pero tenía suyas dos cartas de comanda, una de 
doce cahíces de trigo y otra de ocho, que ya estaban pagadas; y cien sueldos y un cahíz de trigo «sinse carta ninguna».

Debía al alamín de Lucena Mahoma el Carnicero dos cahíces de centeno que le prestó «graciosament»; puntualizó que quería que se le pagaran.

Debía a Juan Sánchez de Sarriá cuatro arrobas de avena.

Debía a Salamon Sumiel un cahíz de trigo, por su hermana Fátima.

Debía a su «entenada» tres cahíces de trigo y once fanegas de avena.

Debía al judío de Oblitas Mayr florín y medio de oro y veinte «grosos de la moneda de Navarra».

Debía a Mosse Sumiel, «por el tallar de las robas» de su casa, seis sueldos, pero tenía que acabar de hacer «un tapet» de su mujer.

Una vez hecha tan detallada relación de sus acreedores, Mahoma de Anzeyt dio los nombres de las personas que le debían, puntualizando sobre algunas que, si lo negaban, se atendrían, no especificó si sus hijos, el merino o el procurador de don Lope, al juramento que prestaran los deudores, sobre si era cierta o no la deuda:

Juan Tirado, cinco cahíces de trigo, resto de ocho que le debía en comanda.

Juan de Bices, cinco arrobas de trigo «sines de carta, fiança» el difunto Miguel Serrano.

Mahoma Cihuena, ochenta sueldos en comanda y doce dineros de un loguero que le logó al alamín de Lucena.

Mahoma Alchinez, cuarenta sueldos, «si dira que no, a su jura».

Muça Nabal, cincuenta sueldos, «si dira que no, a su jura».

Su entenado Mahoma Cabanyas, treinta sueldos, «si dira que no, a su jura».

La del Tanbudo y el que entonces era su marido, ocho florines de oro, pero él tenía en peñora «del, sobre dito deudo, el pedaço de las tapias».

Hamet el Tanbudo, seis arrobas de trigo.

El hijo de Antón Remón, medio cahíz de trigo.

Mahoma el Guaxqui, veinte sueldos, resto de los ciento cincuenta que le prestó en comanda.

Rodrigo de Borja, dos reales de plata.

La mujer del alamín de Aranda, dieciocho sueldos que le prestó, como sabía bien su madre.

Su hermano Mahoma de Anzeyt y su hermana Fátima, ciento sesenta y cinco sueldos de «una junta de bueyes que yo le compre» (sic).

Su hermano Mahoma de Anzeyt y Mahoma el de Pina, diecinueve sueldos «en penyora del, en poder de Abraham Alfrangil, por aquellos e por quaranta sueldos del fillo» del alamín de Morata.

Además, Mahoma de Anzeyt pidió a sus hijos que dieran a su prima, hija de su tía Fátima, doscientos sueldos «de lo mas bien parado que sia en mi 
casa», y a ésta «la piel sania de panyo cardeno». Y no olvidó enumerar el ganado que tenía ${ }^{19}$.

Para hacer tan minuciosa y detallada puntualización de todo lo que adeudaba y se le debía, a veces «sine cartas», Mahoma de Anzeyt tuvo que llevar consigo, cuando fue encarcelado, sus libros de cuentas o pedir que se le entregaran. Su estado de ánimo, ante una posible pena capital, no le hubiera dejado una mente tan clara y expedita.

No me consta el final que le tenía reservado el destino a Mahoma de Anzeyt ni si seguía prisionero en casa del merino o había sido condenado a muerte el 23 de marzo. Día en que su hijo Ali recibió en comanda del judío Abraham Alfrangil seis cahíces una arroba de trigo ${ }^{20}$. Me inclino a pensar que ya había muerto el 5 de noviembre, porque fue precisamente ese día cuando «el fillo del Marrachano», seguramente «con gran dolor» ${ }^{21}$, pagó al notario Martín de Marín ocho sueldos «por el testament de su padre» ${ }^{22}$.

La detención de Mahoma de Anzeyt, alias «el Marranchano», su encarcelamiento en Épila y su condena tuvieron que ser un gran escándalo en la villa y en su lugar de residencia, Lucena. Las dos comunidades de moros y quienes lo conocieron vivirían esos hechos con intensidad e inquietud y los comentarios y chismes en torno al caso serían de todo tipo.

Fuera cuál fuera el final de Mahoma de Anzeyt, la situación de su familia no parecía muy boyante, a tenor de las comandas que su hijo Ali siguió recibiendo ${ }^{23}$. Pero esa es cuestión que queda fuera del objetivo que me propuse cuando inicié este trabajo.

${ }^{19}$ LA.APN., Martín de Marín, 1466, fols. 10v-13: testigos, Juan Sánchez de Sarriá y el moro Ali Adolaziz.

${ }^{20}$ Dicho notario y año, fol. 22v.

${ }^{21}$ Como el que sintió el 27 de junio de 1469 Martín de Marín, el notario que nos ha proporcionado las noticias sobre nuestro personaje, cuando murió su «amada muller» María Navarro. En su protocolo anotó: «yo romango con vira e gran dolor» (dicho notario, 1469, fol. 24v).

${ }^{22}$ Dicho notario, 1466 , fol. 89v.

${ }^{23}$ Entre otras: el 24 de diciembre de ese mismo año le entregó el judío de Tauste Saya Sumiel, menor de días, cuarenta y cinco sueldos, de los que respondió con un rocín «de pelo castanyo» (dicho notario, 1466, fol. 107v); y tres años después, concretamente el 10 de febrero de 1469, era la judía Acli de Gallur, mujer de Salamon Sumiel, la que le daba dos cahíces y medio de trigo y cuatro cahíces cinco fanegas de ordio, «mesura de Epila» (dicho notario, 1469, fol. 10). 